\title{
Application of Multi-Objective Optimization Based on Genetic Algorithm for Sustainable Strategic Supplier Selection under Fuzzy Environment
}

\author{
Muhammad Hashim ${ }^{1}$ (D), Muhammad Nazam² (D), Liming Yao ${ }^{3}$ (D), Sajjad Ahmad Baig ${ }^{1}$, \\ Muhammad Abrar ${ }^{4}$ (iD), Muhammad Zia-ur-Rehman ${ }^{1}$ (iD \\ ${ }^{1}$ Department of Management Sciences, National Textile University Faisalabad (Pakistan) \\ ${ }^{2}$ Institute of Business Management Sciences, University of Agriculture Faisalabad (Pakistan) \\ ${ }^{3}$ Uncertainty Decision-Making Laboratory, Sichuan University Chengdu (China) \\ ${ }^{4}$ Department of Industrial Management, Government College University Faisalabad (Pakistan) \\ bashimscu@gmail.com, nazim ehsas@yahoo.com,.lmyao@scu.edu.cn, sajjad.baig@botmail.com, \\ abrarphd@gmail.com, mzrehman@ntu.edu.pk
}

Received: September 2016

Accepted: February 2017

\section{Abstract:}

Purpose: The incorporation of environmental objective into the conventional supplier selection practices is crucial for corporations seeking to promote green supply chain management (GSCM). Challenges and risks associated with green supplier selection have been broadly recognized by procurement and supplier management professionals. This paper aims to solve a Tetra "S" (SSSS) problem based on a fuzzy multi-objective optimization with genetic algorithm in a holistic supply chain environment. In this empirical study, a mathematical model with fuzzy coefficients is considered for sustainable strategic supplier selection (SSSS) problem and a corresponding model is developed to tackle this problem.

Design/methodology/approach: Sustainable strategic supplier selection (SSSS) decisions are typically multi-objectives in nature and it is an important part of green production and supply chain management for many firms. The proposed uncertain model is transferred into deterministic model by applying the expected value measure (EVM) and genetic algorithm with 
weighted sum approach for solving the multi-objective problem. This research focus on a multiobjective optimization model for minimizing lean cost, maximizing sustainable service and greener product quality level. Finally, a mathematical case of textile sector is presented to exemplify the effectiveness of the proposed model with a sensitivity analysis.

Findings: This study makes a certain contribution by introducing the Tetra ' $S$ ' concept in both the theoretical and practical research related to multi-objective optimization as well as in the study of sustainable strategic supplier selection (SSSS) under uncertain environment. Our results suggest that decision makers tend to select strategic supplier first then enhance the sustainability.

Research limitations/implications: Although the fuzzy expected value model (EVM) with fuzzy coefficients constructed in present research should be helpful for solving real world problems. A detailed comparative analysis by using other algorithms is necessary for solving similar problems of agriculture, pharmaceutical, chemicals and services sectors in future.

Practical implications: It can help the decision makers for ordering to different supplier for managing supply chain performance in efficient and effective manner. From the procurement and engineering perspectives, minimizing cost, sustaining the quality level and meeting production time line is the main consideration for selecting the supplier. Empirically, this can facilitate engineers to reduce production costs and at the same time improve the product quality.

Originality/value: In this paper, we developed a novel multi-objective programming model based on genetic algorithm to select sustainable strategic supplier (SSSS) under fuzzy environment. The algorithm was tested and applied to solve a real case of textile sector in Pakistan. The experimental results and comparative sensitivity analysis illustrate the effectiveness of our proposed model.

Keywords: multi-objective programming, sustainable strategic supplier selection, expected value measure, genetic algorithm, textile sector

\section{Introduction}

Nowadays, sustainable strategic supplier selection (SSSS) is an essential issue for building up a successful supply chain network in a textile sector due to hygienic concerns. It is a key process of supply chain management and also the right suppliers selection play a substantial role for improving overall performance. The process of sustainable manufacturing involves the production of sustainable items and 
the sustainable manufacturing of all the products. Consequently, the sustainable strategic supplier evaluation process must include manufacturing of renewable energy, energy efficiency, green building, and other green and social equity-related products and secondly it focuses on the sustainable manufacturing of all products with consideration of full life cycle stages of product manufactured. In supply chain planning, a decision maker must consider choices with respect to the selection of the right suppliers and their order allocations. Supply chain management (SCM) can be characterized as a procedure with the flow, transportation and services from the production site to consumption site (Buyukozkan \& Cifci, 2011). In fact, the suppliers assume a critical part to achieve the goals of supply chain and the successfully accomplishment of a supply chain is very subject to decision of suppliers. The right selection of sustainable strategic partner enhance the customer satisfaction level and also the supply chain performance in different ways like including lean management, enhancing quality to attain zero defects level, enhancing adaptability to meet the needs of the green consumers, decreasing delivery time at various phases of supply chain.

The sustainable strategic supplier selection issue has acquired significant consideration in the area of academic research (Buyukozkan \& Cifci, 2011; Weber \& Currint, 2003; Kaslnqam \& Glee, 2006; Wu, 2008; Liao \& Rittscher, 2007). Gaballa (1974) is the principal creator who developed mixed integer programming concept for minimizing the aggregate discounted cost of apportioned items to the suppliers for suppliers' election problems in a literal case. He investigated a single-objective with mixedinteger programming for minimizing the sum of purchasing, transportation and inventory costs by considering the vendors delivery, quality and capacity characteristics. Karpak, Kumcu \& Kasuganti (1999) presented a goal programming concept for minimizing costs and maximizing the delivery reliability with quality in the selection of suppliers and in allocating the quantities to every selected supplier.

Degraeve and Roodhooft (2000) presented an aggregate cost technique with numerical programming to treat supplier section problem using action based cost data. Ghodsypour and O'Brien (2001) investigated a mixed-integer non-linear programming model for minimizing total logistics cost, for example price, storage, ordering and transportation costs.

However, in the real world situation for supplier determination issue numerous data identified with parameters are not known absolutely. The decision makers usually face a high degree of uncertainties in decision making. These difficulties expanded the significance of stochastic and fuzzy programming for taking care of these present reality issues where information are not known exactly. Deterministic models cannot be suitable to solve the problems in this situation for obtaining an effective solution. As well as, it is extremely troublesome for the decision makers to clarify the requirements in points of interest or in details, which adds uncertainty to the supplier section. Moreover, for the improvement of E-business, the cost of various things are distinctive in various regions, even the value that the same supplier is given for 
the most part differ from day to day. Therefore, a high degree of uncertainty deriving from the incomplete information should be considered very carefully during the selection procedure. In these situations, fuzzy set theory is the most suitable option for dealing with uncertainty.

In these cases, fuzzy set theory is one of the best tool for handling the uncertainty. For example, it is very difficult for decision maker to determine the demand, cost and quality in advance because the values of these parameters changed with the passage of time and not remain the same. In this situation, the fuzzy set theory can be used because of the comportment of unclearness and imprecision of data in the supplier choice issue. Fuzzy set theory has got the attention of the researchers by Zadeh (1965) and after that he presented possibility theory and number of scholars are influenced by this theory, such as Dubois and Prade (1997a, 1997b). It has been employed in a wide assortment of genuine issues. Many scholars have studied this uncertainty and imprecision by using fuzzy theory (Amid, Ghodsypour \& Brien, 2006; Kumar, Vrat \& Shankar, 2006). However, most supplier selection techniques covered in the literature suppose the studying parameters are deterministic and known (Aissaoui, Haouari \& Hassini, 2007). Just a limited number of studies deal the stochastic and imprecision existed in data associated with supplier selection decision. Such as Jafar, Songhori and Mohammad (2009) investigated fuzzy group decision making/linear programming structure for supplier selection issue and order allocating, Liao et al. presented a comprehensive multi-objective supplier selection framework under stochastic conditions by considering uncertainties of demand quantity and time. Wen \& Chi (2010) investigated a methodology using fuzzy decisions making and AHP strategy.

Hashim, Yao, Nadeem, Nazim \& Nazam (2014) introduced a multi-objective optimization framework to deal with supplier selection problem under fuzzy environment. Kilic (2013) investigated an integrated technique to deal with supplier selection in multi-item/multi supplier environment. He researched a mixed integer liner programming and fuzzy TOPSIS methods to select a suitable supplier in multiples supplier environment. Liou, Chuang \& Tzeng (2013) presented a novel fuzzy integer-based model that addresses the interdependence among the various criteria and employs the non-additive gap-weighed analysis. Above all the discussed models to deal with the supplier selection issue played an important role for solving the real problems.

In the literature there exist a lot of approaches/techniques to solve the problem of sustainable supplier selection but most of the approaches are based on multi-criteria decision making frameworks (Memon, Lee \& Mari, 2015; Wang-Chen, Chou, Luu \& Yu, 2016; You, You, Liu \& Zhen, 2015; Banaeian, Mobli, Fahimnia, Nielsen \& Omid, 2016). The fundamental reason for applying the decision making models is that both alternatives and criteria are fixed a priori and that decision happens once. This basic assumption definitely limits the accuracy of the results, mostly when the values change with the passage of time and the pair-wise decision matrix is not fixed or static as in sustainable supplier selection topics. Also, the 
fuzzy multi-criteria group decision-making model belief of the supplier selection mainly concentrates on the cause and effect relationship between the components of systems individually; therefore, it is not considered as a broader model. Fuzzy Multi-criteria decision making frameworks basically does not provide a comprehensive understanding of the complicated nature of the (SSSS) problem with respect to the set of criterion, i.e. political, economic, social and environmental factors (Amin \& Zhang, 2012; Awasthi, Chauhan \& Goyal, 2010; Buyukozkan \& Cifci, 2011; Chang, Chang \& Wu, 2011; Foerstl, Reuter, Hartmann \& Blome, 2010). Therefore, from the above discussion it is revealed that multi-criteria decision making models cannot be most reliable source for selecting the suppliers for a long time period.

In this research, a fuzzy multi-objective model is presented for the sustainable strategic supplier selection (SSSS) issue in fuzzy environment. The purchase directors can allot diverse weights for numbers of criteria with a specific end goal to oversee stream of green supply materials and enhance quality, service and decreased expense, keeping in mind the end goal to enhance the supply chain performance. This study contributes to present research in the following ways: first, a multiple objectives technique is presented which considers multiple and conflicting objective functions for solving supplier selection problem in better way. Furthermore, demand, costs, service and quality levels are characterized by fuzzy variables which help decision makers to take more effective and precise decisions in fuzzy environment.

As mentioned previously in the literature review, there is a lack of methodologies which concentrate on the various sources of uncertainty in an optimization way, and few researches investigate the supplier selection problem by integrating the objectives including cost, quality and service level in a fuzzy environment. Hence in this study we developed a sustainable strategic supplier selection model based on genetic algorithm to solve the real world problem in a textile sector of Pakistan.

The main contributions of this research can be summarized as follows:

- Introducing a novel fuzzy multi-objectives model based on genetic algorithm by incorporating lean cost, sustainable service and greener product quality level in an eco-supply chain network.

- Achieving a model which contemplates the different sources of uncertainty affecting supplier selection in a textile sector by considering the preferences of decision makers in the proposed data.

- Applying the optimization model to a real world textile supply chain dedicated to the issues of sustainable strategic supplier selection.

The remainder of the paper is organized as follows: part second comprised of sustainable strategic supplier selection (SSSS) problem under fuzzy environment; part third discuss mathematical programming model in fuzzy environment and expected value operator to deal with fuzzy parameters for 
converting the multi-objective programming model into the crisp equivalent model; part 4, explains the genetic algorithm as a solution approach for solving proposed model; part 5 introduces a numerical example with sensitivity analysis and outcomes for showing the application of material supply problem, and finally, the concluding comments with future directions are given in last part.

\section{Key Problem Description}

For managing supply chain, the manufacturer (Textiles Company) need to purchase green raw materials or different items from various suppliers and take an assortment of supplier properties, for example, quality, price and service level into consideration. An individual supplier has diverse execution qualities because of various criteria. For example, the supplier who can supply a thing at the slightest per unit cost might not have the best quality or service level than the other contending suppliers. It is clear that there could be a few deviations in the nature of various items offered by an alternate supplier. That's, might be some product of a supplier can have better quality however can be more costly when compare it with comparable product of alternate suppliers. The sustainable strategic supplier selection (SSSS) problem manages issues identified with the finding of right suppliers and their portion allocations. A strategic supplier finding can improve the supply chain performance as well as make a solid framework which can give an intense backing to purchaser for accomplishing his objectives. It is a complex problem because of various reasons, by nature, this is a multi-criteria decision making problem. So the managers may be adopted different criteria for different kinds of material. However, to select right (potential) suppliers always confuse the managers in case of many kinds of candidates and materials.

The supplier selection problem (SSP) in fuzzy environment can be expressed as follows: assume that the manager want to choose the supplier from candidates and some differentiations between them are price, quality and service levels. The manager needs to know which suppliers should be selected and how much of the quantity $Y_{i j}$ should be ordered considering the objectives. However, as to the supplier selection problem, it is hard to describe the cost and demand as known values because there is not sufficient data available to analyze, which usually cause uncertainty, imprecise or vague situation (Xu \& Yan, 2011; Jauhar, Pant \& Abraham, 2014; Khatie, Bulgak \& Segovia, 2010; Lee, Kang, Hsu \& Hung, 2009; Ordoobadi, 2009; Qiang, Hui \& Xiao-Dong, 2013; Tako \& Robinson, 2012; Alinezad, Seif \& Esfandiari, 2013; Baskaran, Nachiappan \& Rahman, 2012). Considering this situation, we use fuzzy variable to describe uncertain, imprecise or ambiguous information in the (SSSS) problem. This research work concentrates on developing an expected programming method for supplier selection in fuzzy environment, in which different weights can be allocated to different objectives for showing their importance in decision making (Chen, Lin \& Huang, 2006; Chu \& Varma, 2012; Govindan, Khodaverdi 
\& Jafarian, 2013; Hashemian, Behzadian, Samizadeh \& Ignatius, 2014; Rezaei \& Ortt, 2012; Rodríguez, Ortega \& Concepción, 2013).

In this problem, a Pakistani vertically integrated textile manufacturing company is chosen for this research. The proposed firm has approximately 6000 employees per shift; they manufacture garments products such as sportswear, sleep-wear, underwear, pants and trousers. The chosen firm is one of the leaders in its product segment in Pakistan; its main customers are major national and international retailers. This company has enacted various changes in the structure of the final product in order to make it comfortable, free of harmful chemicals and toxic materials, and to lower its price by providing greener quality. These changes, in turn, meet both environmental legislation regulations and the demands of their customers.

This problem deals in achieving the following highlighted objectives:

1. To identify and understand the concept of environmental sustain-ability associated with the strategic supplier at industrial context in textile firms.

2. To evaluate the identified criterion to priority by determining and confirming of their relative importance in effective selection of (SSSS).

3. To interpret the fuzzy logic for dominance of one objective over the other for the formulation of multi-objective optimization based on genetic algorithm for sustainable strategic supplier selection with sensitivity analysis under fuzzy environment.

In Pakistan, according to the 2016 National Policy on Solid Waste, all industries in the textile sector are now required to take responsibility for their post-consumer products take-back and environmental impacts. Because of the Pakistani governments mandate, companies recognize that offering greener textile products not only meets customer demand but also requires locating good green suppliers to improve their supply chain management. In this paper, the parameters are characterized by fuzzy variables that can explain uncertain and imprecise data at the decision time for handling with complex uncertain problems in practical cases. In real situation, decision makers for taking the decision face an environment where the information about the study objectives, constraints (parameters) are not available precisely.

Based on the above perspectives, some researchers (Shidpour, Shahrokhi \& Bernard, 2013; Singh, 2014; Soroor, Tarokh, Khoshalhan \& Sajjadi, 2012; Iranmanesh \& Thomson, 2008; Aissaoui et al., 2007; Kannan, Khodaverdi, Olfat, Jafarian \& Diabat, 2013; Awasthi, Chauhan \& Goyal, 2011) pointed out that in the present reality decision making issues in (SSSS) problems, one often takes place in an uncertain environment. It is hard to report the problem parameters as known because of the complexity of environment socially and economically and at the same time some unpredictable factors for example bad 
weather and machine or vehicle breakdowns. These disputes expanded the significance of stochastic and fuzzy programming techniques for solving real issues where information are not known correctly. For instance, it is not easy for a decision maker to give the accurate information about his needs, however as indicated by his experience, he can gauge the requirement for one thing as an interval with the possible values, this explanation is a case of fuzziness. Such a large number of parameters such as time, demand and cost are normally unverifiable instead of deterministic and it is exceptionally hard to decide accurate figure of these parameters because of the variance in the values. In real problems, the decision maker cannot gather the ideal data for every parameter. As various individuals have diverse feeling about the uncertain variables brought on by the unverifiable environment, and there is no plain meaning of this change. Consequently in such kind of issues, it can be described by the uncertainty of fuzziness. Numerous researchers have mentioned this instability and imprecision and deal with them by using fuzzy theory (Fazlollahtabar, Mahdavi, Ashoori, Kaviani \& Mahdavi-Amiri, 2011; Kannan et al., 2013; Songhori, Tavana, Azadeh \& Khakbaz, 2011; Hashemian et al., 2014; Katagiri, Sakawa, Kato \& Nishizaki, 2008; Amid et al., 2006; Su, Yang \& Pearn, 2011). However, supplier selection issue often times confronted with environmental uncertainty where fuzziness exist in decision making. In such kind of situations, fuzzy variables are a best option for describing the uncertainty of decision variables.

In this research, demand, cost, quality level and service level are uncertain parameters and interpreted by fuzzy variables that can be further described by triangular fuzzy numbers. It is very difficult for a decision maker to get the accurate data for all uncertain variables. So in this circumstance, the decision maker can depict the parameters into triangular fuzzy numbers that are more suitable to clarify the instability, for example, demand is about $D_{m}$ but emphatically not less than $D_{l}$ and large than $D_{u}$.

\section{Model Formulation}

In this paper, the problem is formulated as a multi-objectives programming problem with fuzzy coefficients, in which the decision makers have three objectives first minimize the cost and second maximize greener product quality and third maximize the sustainable service level.

In real life problems, input data is generally imprecise because of incomplete information. In an expert's decision making scenario, mostly the usage of fuzzy linguistic variables are preferable instead of numerical or stochastic data. It is the best options for the decision makers to tackle the subjectivity that often exist in the process of supplier selection. Therefore, if we want to consider the uncertainty, especially subjective uncertainty, fuzzy variables can be employed (Xu \& Zhou, 2011). In this research, the parameters used in the proposed model are characterized by fuzzy variables for handling subjective uncertainty. 


\subsection{Assumptions and Notations}

To model the sustainable strategic supplier selection (SSSS) problem for green material supply in a fuzzy environment, the following assumptions are considered:

1. Quantity discount is not considered.

2. Purchasing is limited to three kind of goods.

3. Cost, demand, and quality are characterized by fuzzy variables.

4. Each supplier can be selected for more than one product.

Suppose that there is one buyer, $i$ suppliers. The task is to allocate the orders to suppliers for minimizing cost and maximizing the green material quality.

\section{Indices:}

$\Omega$ : set of suppliers, $i$ is an index, $i \in \Omega=\{1,2,3, \ldots, I\}$;

$\Upsilon:$ set of products, $j \in \Upsilon=\{1,2,3, \ldots, J\}$;

\section{Parameters:}

$\tilde{D}_{i:}$ : aggregate demand of the item over the period from supplier $i$;

$\tilde{P}_{i j}$ : unit price of the order quantity $Y_{i j}$ from the supplier $i$;

$\tilde{Q}_{i j}$ : product quality level of $i t h$ supplier for product $j$;

$\tilde{S}_{i j}$ : product service level of $i t h$ supplier for product $j$;

A: budget allocated to suppliers $i$;

$a_{i j}$ : capacity of $i t h$ supplier for greener product $j$;

\section{Decision variables:}

$Y_{i j}$ is the variable which denotes the number of units purchased from the $i t h$ supplier;

For the proposed problem, there is a need to allocate the order to suppliers from the potential set 1, 2, $3, \ldots, I$. 


\subsection{Modeling Formulation}

Based on the manager's objectives in the proposed problem and the notations mentioned above, this study develop a multi-objective optimization model to attempt it.

In this study, the first objective function is to minimize the total cost for ordering the demand, which will be counted the basic economic aim to the supplier selection problem in material supply.

$$
\min F_{1}=\sum_{i=1}^{I} \sum_{j=1}^{J} E\left[\tilde{P}_{i j}\right] Y_{i j}
$$

Second objective function maximizes the suppliers environment friendly product quality. To make sure that the production process can be carried through smoothly, the managers require that the quantity of rejected things ought to be kept at a low level. Since, a textile factory has a limited time to complete a customer demand in order to cope the penetration of competitors. So, the supplier items quality level should be considered very carefully when decision makers make the decision on the problem of suppliers selection.

$$
\max F_{2}=\sum_{i=1}^{I} \sum_{j=1}^{J} E\left[\widetilde{Q}_{i j}\right] Y_{i j}
$$

Third objective function maximizes the sustainable supplers service level. The late delivery items can affect the supply chain performance and supply chain visibility. Since a factory or a textile project needs a lot of manpower and material, the cost can be increased by late delivery. Hence, the supplier effective service level should be considered seriously when decision makers make the decision on the problem of strategically fit supplier's selection.

$$
\max F_{2}=\sum_{i=1}^{I} \sum_{j=1}^{J} E\left[{\widetilde{S_{i j}}}\right] Y_{i j}
$$

Generally speaking, some compulsory conditions must be fulfill when the decision maker takes the decision. In this research, the required conditions are listed below:

The first constraint states that the total supply must be meet the expected demand.

$$
\sum_{i=1}^{I} \sum_{j=1}^{J} Y_{i j} \geq E\left[\tilde{D}_{i j}\right]
$$

Second constraint states that the total cost should be within expected budget amount.

$$
\sum_{i=1}^{I} \sum_{j=1}^{J} E\left[\tilde{P}_{i j}\right] Y_{i j} \leq A_{j}
$$


Third constraint states that order quantity should be less than the suppler capacity.

$$
Y_{i j} \leq a_{i j}
$$

Fourth constraint states the non-negativity constraints on decision variable.

$$
Y_{i j} \geq 0
$$

It is generally a very difficult task to solve the optimization problems with multi-objective under uncertainty (fuzzy environment). For solving the fuzzy model, the first step is to convert the fuzzy values into certain (deterministic) form. In this study, the expected value model (EVM) is adopted that based on Me for solving the presented problem. The study parameters are defined in triangular form and for solving them we used a new fuzzy measure with an optimistic-pessimistic adjusting index. The explanation of this fuzzy measure Me can be studied in Orji and Wei (2014) and Dubois and Prade (1994). This is a convex combination of possibility (Pos) and necessity (Nec). The basic information about these measures can be studied in Wang \& Fang (1997). Let $D=\left(b_{1}+b_{2}+b_{3}\right)$ denotes a triangular fuzzy variable. According to the definition and properties of expected value operator of fuzzy variable using measure $M e(\mathrm{Xu} \& \mathrm{Ding}, 2011)$, if there is a fuzzy variable $D=\left(b_{1}+b_{2}+b_{3}\right)$, where $b_{1}, b_{2}, b_{3}>0$, so the expected value of $D$ can be written as:

$$
E^{M e}[\tilde{k}]=\frac{1-\lambda}{2}\left(r_{1}+r_{2}\right)+\frac{\lambda}{2}\left(r_{2}+r_{3}\right)
$$

According to the above explanation, by integrating of Equations (1) to (7), multi-objective expected value model can be formulated as follows:

$$
\left\{\begin{array}{l}
\min F_{1}=\sum_{i=1}^{I} \sum_{j=1}^{J} E^{M e}\left[\widetilde{P}_{i j}\right] Y_{i j} \\
\max F_{2}=\sum_{i=1}^{I} \sum_{j=1}^{J} E^{M e}\left[\widetilde{Q}_{i j}\right] Y_{i j} \\
\max F_{3}=\sum_{i=1}^{I} \sum_{j=1}^{J} E^{M e}\left[\widetilde{S}_{i j}\right] Y_{i j} \\
\text { s.t. }\left\{\begin{array}{l}
\sum_{i=1}^{I} \sum_{j=1}^{J} Y_{i j}=E^{M e}[\widetilde{D}] \\
\sum_{i=1}^{I} \sum_{j=1}^{J} E^{M e}\left[\widetilde{P}_{i j}\right] Y_{i j} \leq A \\
Y_{i j} \leq a_{i j} \\
Y_{i j} \geq 0
\end{array}\right.
\end{array}\right.
$$


It is not simple to find an optimal solution for a multi-objective optimization model. In such kind of problems we need to assign a weight to each objective for normalization. So, in this study, the weighted sum method is adopted to solve the multi-objective optimization problem. Suppose that $w_{i}$ is a weighted coefficient for $f_{i}(y)$ objectives functions and the sum of $w_{i}$ will be equal to 1 . It expresses the importance of objective functions in the proposed model. Model can be converted into single objectives using the following process.

$$
f(y)=\sum_{i=1}^{m} w_{i} f_{i}(y)
$$

The weighted equation can be written as:

$$
\min (f(y))=\min _{y \in Y} w_{1} f_{1}(y)+\left(-\max _{y \in Y} w_{2} f_{2}(y)\right)+\left(-\max _{y \in Y} w_{3} f_{3}(y)\right)=\sum_{i=1}^{m} w_{1} f_{1}(y)
$$

\section{Solution Procedure}

Many kinds of evolutionary computation techniques are developed for solving the composite optimization problems. Genetic algorithm is one of them and a well-known form of evolutionary algorithms. It does not require the sated information should be in form of gradient about the objective functions for optimization and it can also provide a number of possible solutions for solving the problem and the final decision depend on decision makers. From last three decades, it has been gained a significant success in providing smart solutions to several complicated optimization issues (Jauhar et al., 2014; Khatie et al., 2010). It belongs to stochastic search methodology that commonly used for the optimization of objectives for studying problems. It is supported by the mechanics of natural selection and natural genetics-survival of the fitness function values. The advantage of this approach enables us to obtain the best optimal solution globally.

Furthermore, it does not required the particular mathematical analysis of optimization issues that makes it simple coded by users who are not necessarily expert at mathematical and algorithms. It has been applied for solving different kind of problems, such as transportation problems, facility layout problems, supplier selection, scheduling, network optimization and so on. Due to the subjective study, development of genetic algorithm approach is necessary to solve out the supplier selection problem. The proposed approach to be considered the best option for optimizing fuzzy model. So, GA is a most suited solution method for getting the good result of the proposed model.

The next section under takes to present GA to solve the multi objective programming model with fuzzy coefficients. The detail discussion as follows: 
Step 1. Initialize the Population: Randomly generated population called chromosomes. These chromosomes represent the solution of the optimizing objectives. The chromosomes are denoted by vector $\mathrm{y}, y=\left(y_{1}, y_{2}, y_{3}, \ldots, y_{\text {Npop }}\right)$.

Step 2. Handling the constraints: Fuzzy simulation is used for checking the chromosome generated by genetic operator for seeing that the chromosomes are in the feasible region. Generate random vector $y$ within the possible region till a possible one is accepted as a chromosome. Run the above process for $N_{\text {pop-size }}$ times for getting the initial feasible chromosomes $y_{1}, y_{2}, y_{3}, \ldots, y_{N-p o p s i z e .}$

Step 3. Evolution function: For the evolution of each chromosomes the following function is applied for calculating the fitness function values for each chromosomes.

$$
\operatorname{eval}(y)=\sum_{k=1}^{m} \frac{E\left[f_{k}(y, \xi)\right]-z_{k}^{\max }}{z_{k}^{\max }-z_{k}^{\min }}
$$

Step 4. Selection: Holland (Lee et al., 2009) developed roulette wheel selection concept for dealing with selection probability for each chromosome. In this research we apply roulette wheel selection process for developing selection process. The wheel will roulette $N_{\text {pop-size }}$ times and every time a single chromosome is selected for a new population. The procedure as follows: Calculate the total probability $q_{i}$ for each chromosome $y^{i}$

$$
q_{0}=0, \quad \mathrm{q}_{i}=\sum_{j=1}^{i} \operatorname{eval}\left(y^{i}\right), i=1,2, \ldots N_{p o p-s i z e}
$$

Randomly generate a random number $\gamma$ in range $[0,1]$ and select the $i t h$ chromosome $y^{i}$. Run the above procedure $N_{\text {pop-size }}$ times for getting the $N_{\text {pop-size }}$ pairs of chromosomes.

Step 5. Crossover and mutation operations: These operations are used for updating the chromosomes. The crossover, operation is started from generating a random number $\gamma$ from the open interval $(0,1)$, chromosomes $y^{i}$ will be selected as a parent if $\gamma<p_{c}$, here $p_{c}$ is a parameter which is used defined as the crossover probability. The selected parents are denoted by $y^{1}, y^{2} \ldots$

After that a random number is generated from open interval $(0,1)$ and then the crossover operator work on $y^{1}$ and $y^{2}$, in result it produced two children $D_{1}$ and $D_{2}$ as follows:

$$
D^{1}=c y^{1}+(1-c) y^{2}, D^{2}=c y^{2}+(1-c) y^{1}
$$

In case of the resulted children are feasible, it will replace the parents with them. Otherwise, redo the crossover operation with another random number $c$ until the given number of cycles is not over. In second process named mutation operation, repeat the same process (steps) like crossover process from 
$i=1$ to pop-size, the chromosome $y^{i}$ is selected as a parent to undergo the mutation operation provided that random number $\gamma<p_{m}$ in which $p_{m}$ is defined as the mutation probability parameter. $P_{m} . N_{p o p-s i z e}$ chromosomes are expected to be selected after repeating the process $N_{p o p-s i z e}$ times. Change each selected parent, denoted by $s=y^{1}, y^{2}, \ldots, y^{i}$ in the following process. Randomly choose a mutation direction $d \in R^{n}$. Replace $S$ with $S+M . d$ if $S+M . d$ is feasible, otherwise set $M$ as a random number between 0 and $M$ until it is feasible or a given number of cycles is finished. Here, $M$ is an appropriately big positive number.

\section{Practical Application and Sensitivity Analysis}

To demonstrate the applicability of the proposed model, this section presented a numerical case of the Pakistani Textiles sector. For supplying material to a manufacturing plant of a textile industry, we assume that there are five suppliers and three kinds of products that need to be managed. In this problem, Cost, service and quality are the purchasing criteria. The total purchasing cost must be within the given budget and suppliers capacity. It is supposed that the required information about the supplier's performance on the above purchasing criteria is not completely available. It is characterized by fuzzy variables and the related data are shown in Tables 1 and 2 .

\begin{tabular}{|c|c|c|c|}
\hline Product & 1 & 2 & 3 \\
\hline Demand & $(3000,3500,4000)$ & $(3000,3500,4000)$ & $(3000,3500,4000)$ \\
\hline
\end{tabular}

Table 1. The aggregate demand $(\tilde{D})$

\begin{tabular}{|c|c|c|c|c|c|}
\hline Suppliers (i) & Green Product $(j)$ & Price $\tilde{P}_{i j}$ & Quality $\tilde{Q}_{i j}$ & Service level $\tilde{\boldsymbol{S}}_{i j}$ & Capacity \\
\hline 1 & $\begin{array}{l}1 \\
2 \\
3\end{array}$ & $\begin{array}{l}(4.2,4.3,4.4) \\
(5.3,5.4,5.5) \\
(6.3,6.4,6.5)\end{array}$ & $\begin{array}{l}(0.80,0.81,0.82) \\
(0.80,0.81,0.82) \\
(0.80,0.81,0.82)\end{array}$ & $0.88,0.90,0.92$ & $\begin{array}{l}1000 \\
1500 \\
2000\end{array}$ \\
\hline 2 & $\begin{array}{l}1 \\
2 \\
3\end{array}$ & $\begin{array}{l}(4.3,4.4,4.5) \\
(5.3,5.4,5.5) \\
(6.3,6.4,6.5)\end{array}$ & $\begin{array}{l}(0.91,0.92,0.93) \\
(0.91,0.92,0.93) \\
(0.91,0.92,0.93)\end{array}$ & $0.93,0.95,0.97$ & $\begin{array}{l}1000 \\
1500 \\
2000\end{array}$ \\
\hline 3 & $\begin{array}{l}1 \\
2 \\
3\end{array}$ & $\begin{array}{l}(4.4,4.5,4.6) \\
(5.4,5.5,5.6) \\
(6.4,6.5,6.6)\end{array}$ & $\begin{array}{l}(0.92,0.93,0.94) \\
(0.92,0.93,0.94) \\
(0.92,0.93,0.94)\end{array}$ & $0.73,0.75,0.77$ & $\begin{array}{l}1000 \\
1500 \\
2000\end{array}$ \\
\hline 4 & $\begin{array}{l}1 \\
2 \\
3\end{array}$ & $\begin{array}{l}(4.5,4.6,4.7) \\
(5.5,5.6,5.7) \\
(6.5,6.6,6.7)\end{array}$ & $\begin{array}{l}(0.93,0.94,0.95) \\
(0.93,0.94,0.95) \\
(0.93,0.94,0.95)\end{array}$ & $0.78,0.80,0.82$ & $\begin{array}{l}1000 \\
1500 \\
2000\end{array}$ \\
\hline 5 & $\begin{array}{l}1 \\
2 \\
3\end{array}$ & $\begin{array}{l}(4.6,4.7,4.8) \\
(5.6,5.7,5.8) \\
(6.6,6.7,6.8)\end{array}$ & $\begin{array}{l}(0.93,0.94,0.95) \\
(0.93,0.94,0.95) \\
(0.93,0.94,0.95)\end{array}$ & $0.83,0.85,0.87$ & $\begin{array}{l}1000 \\
1500 \\
2000\end{array}$ \\
\hline
\end{tabular}

Table 2. Suppliers quantitative information 


\subsection{Results and Discussions}

Putting the above numerical information into the presented model, we followed GA by using Matlab 7.9 on computer (Pentium 4.2GHz) with 2048 MB memory for testing the effectiveness of the model with the proposed example. We got the satisfactory solution based on $M e$ fuzzy measure by setting $\lambda=0.5$ (optimistic-pessimistic index), population size is 20 and the probability of crossover and mutation are 0.2 and 0.1 simultaneously, fuzzy simulation based GA based is run at the 60 generations for getting the best solution. Inertia weight $W_{1}=0.4, W_{2}=0.3, W_{3}=0.3$. The best results are presented in Table 3. The GA search process for the optimal solution can be seen in Figure 1. The optimal solution depend on the value of $\lambda$ and the different weights assigned to both objects. The decision maker can get the different objective values by changing these parameters.

\begin{tabular}{|c|c|c|c|c|c|c|}
\hline$W_{1}$ & $W_{2}$ & $W_{3}$ & $F_{1}^{*}$ & $F_{2}^{*}$ & $F_{3}^{*}$ & Fitness value \\
\hline 0.4 & 0.3 & 0.3 & $5.6524 \mathrm{e}+04$ & $1.0321 \mathrm{e}+04$ & $9.3292 \mathrm{e}+03$ & $2.9462 \mathrm{e}+04$ \\
\hline
\end{tabular}

Table 3. The optimal objective values of the case problem

\begin{tabular}{|c|c|c|c|}
\hline \multirow{2}{*}{ Supplier } & \multicolumn{2}{|c|}{ Items } \\
\cline { 2 - 4 } & 1 & 2 & 3 \\
\hline 1 & $Y_{11}=222$ & $Y_{12}=521$ & $Y_{13}=1273$ \\
\hline 2 & $Y_{21}=950$ & $Y_{22}=374$ & $Y_{23}=162$ \\
\hline 3 & $Y_{31}=893$ & $Y_{32}=1120$ & $Y_{33}=1030$ \\
\hline 4 & $Y_{41}=164$ & $Y_{42}=1366$ & $Y_{43}=454$ \\
\hline 5 & $Y_{51}=1271$ & $Y_{52}=119$ & $Y_{53}=581$ \\
\hline
\end{tabular}

Table 4. The optimal solution of the case problem 


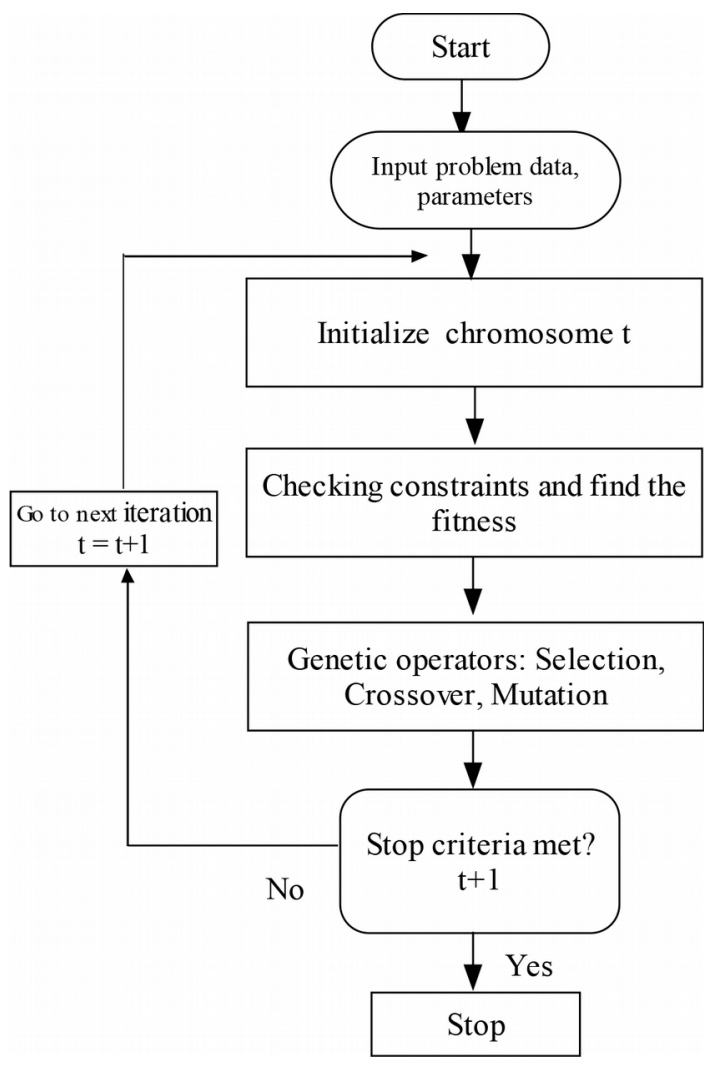

Figure 1. The process of fuzzy simulation-based genetic algorithm

\subsection{Sensitivity Analysis}

The proposed parameters are decided by the estimated data or experts advice to obtain different level solution. We can make the sensitive analysis by changing the decision makers confidence level based on optimistic-pessimistic index. Global market is becoming more and more competitive day by day due to this reason decision maker face rigorous challenges for selecting the supplier in an efficient and cost effective manner. The comparison of the solution is shown in Figure 2, the red line represents the solution using parameter $\lambda=0.8$, the green one using parameter $\lambda=0.5$, the blue one using parameter $\lambda=0.2$. Obviously, the results with the green one showed better results than those with red one presents. Concurring with real experience, the small value can be a better option than a higher. In this situation, the decision makers should have a high risk of uncertainty. According to the above discussion, the parameters value are dependent on decision maker's attitude, he can select according to his preference. Usually, the decision makers select the key suppliers first and then consider the rest of partners with respect to other objectives. 


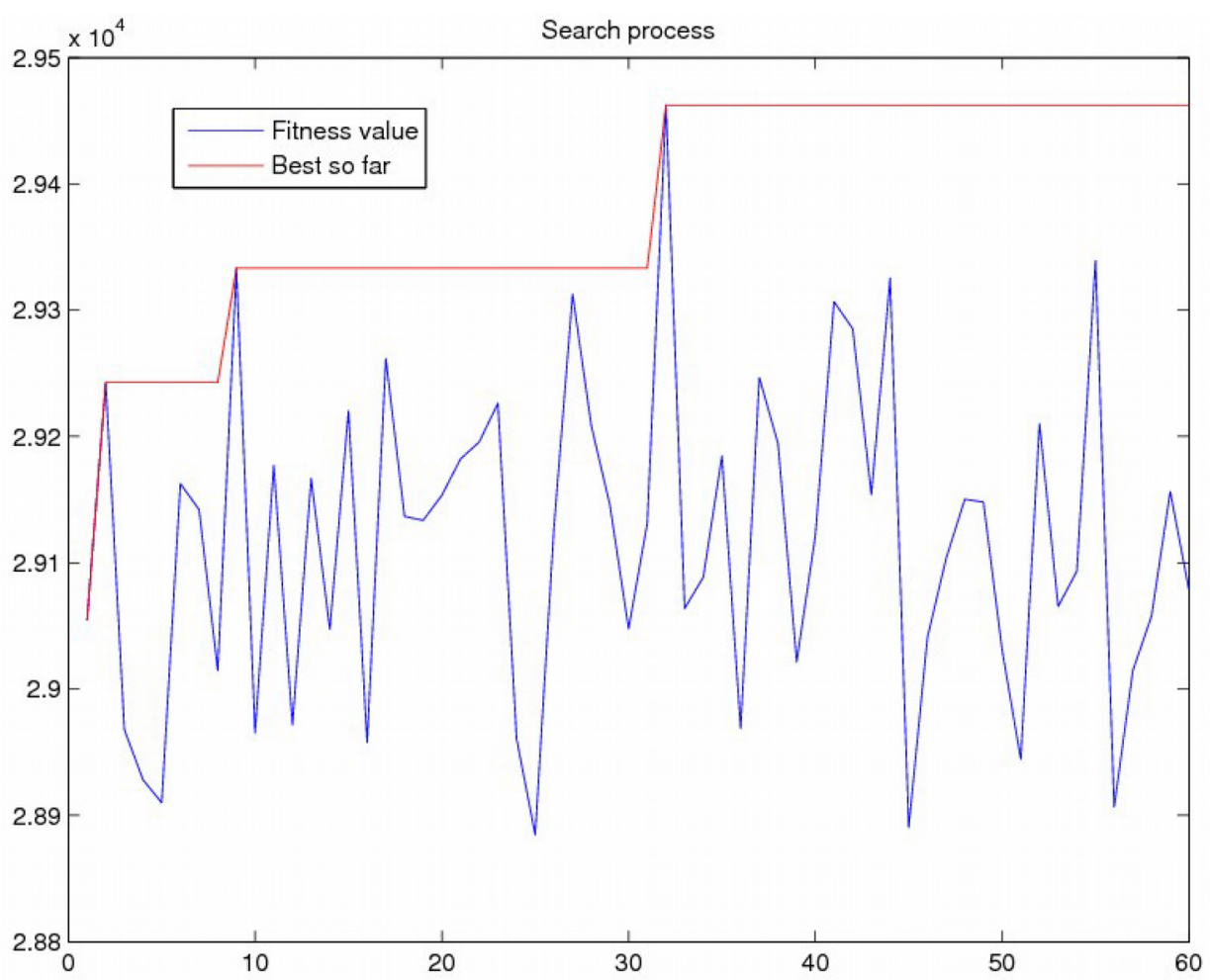

Figure 2. Optimal solution layout (Evolutionary process of the proposed GA approach). Here $\mathrm{X}$-axis denotes the number of generations and $\mathrm{Y}$-axis denotes the fitness function values.

From the procurement and engineering perspectives, minimizing cost, sustaining the quality level and meeting the production time-line is always the main consideration for selecting the supplier. This may facilitate engineers to reduce production costs and at the same time improve their product quality in a sustainable way by enhancing the $\mathrm{R} \& \mathrm{D}$ capability. Therefore, it is very interesting to hear that when the engineers ask the key suppliers for sophisticated technology, the buyer will be able to do so. In brief, this study recommends the buyer to select the suppliers who meet the desired objectives. If the textile company adopts the minimum cost objective as the most important supplier criteria, it may bring the holistic supply chain actors into a risky environment. Consequently, the concept of the minimal cost objective should be replaced by the rest of the strategic sustainable objectives including lead time and eco-product quality. 


\begin{tabular}{|c|c|c|c|c|c|}
\hline$\lambda$ & Weight & $F_{1}^{*}$ & $F_{2}^{*}$ & $F_{3}^{*}$ & Fitness function values \\
\hline 0.2 & $\begin{array}{l}W_{1}=0.4 \\
W_{2}=0.3 \\
W_{3}=0.3\end{array}$ & $5.3566 e+04$ & $9.9018 \mathrm{e}+03$ & $8.9686 e+03$ & $2.8318 \mathrm{e}+04$ \\
\hline 0.5 & $\begin{array}{l}W_{1}=0.4 \\
W_{2}=0.3 \\
W_{3}=0.3\end{array}$ & $5.6524 \mathrm{e}+04$ & $1.0321 \mathrm{e}+04$ & $9.3292 \mathrm{e}+03$ & $2.9462 \mathrm{e}+04$ \\
\hline 0.8 & $\begin{array}{l}W_{1}=0.4 \\
W_{2}=0.3 \\
W_{3}=0.3\end{array}$ & $6.0015 e+04$ & $1.0511 \mathrm{e}+04$ & $1.0554 \mathrm{e}+04$ & $3.0959 e+04$ \\
\hline
\end{tabular}

Table 5 . Sensitivity with respect to parameter $\lambda$

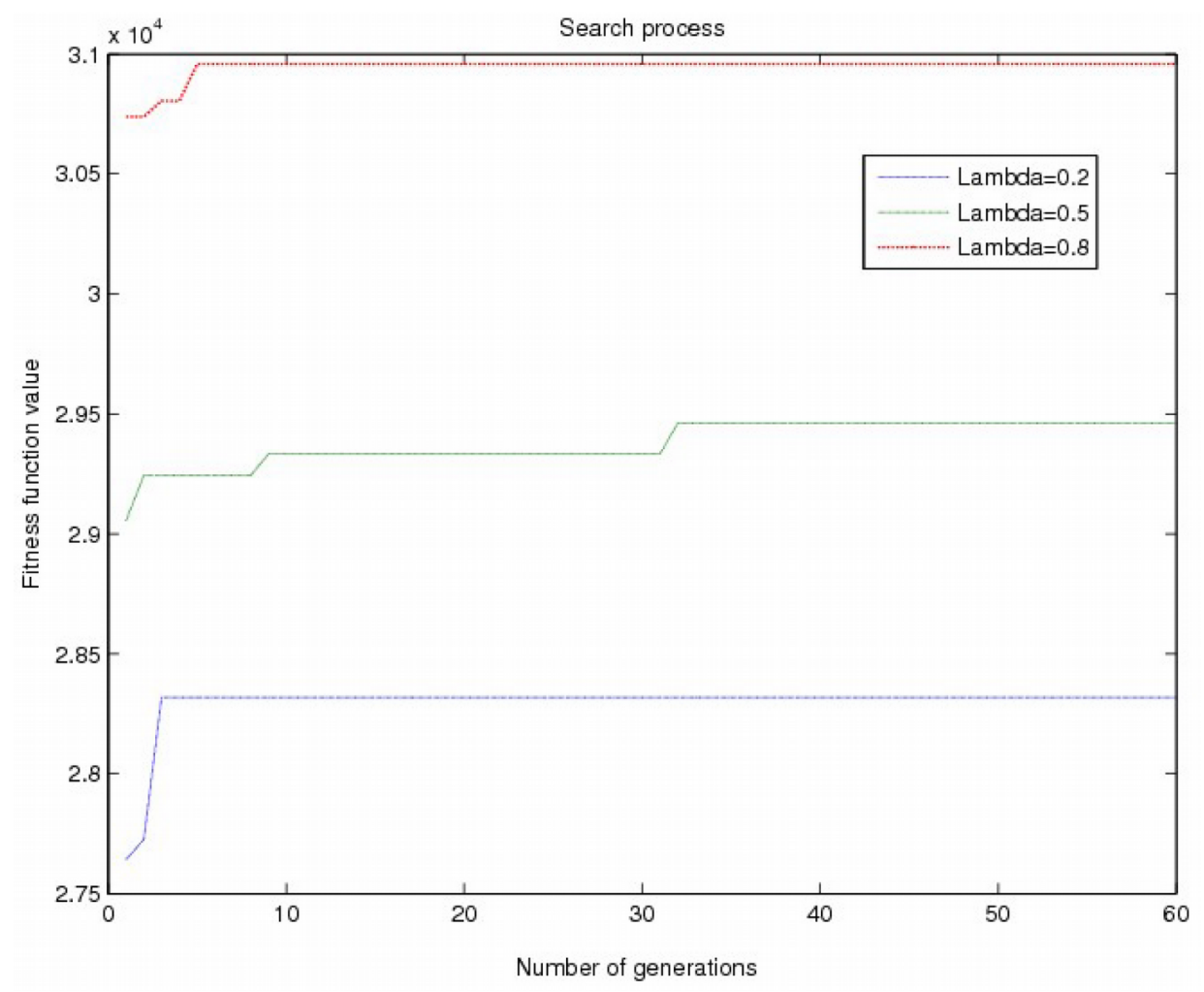

Figure 3. Solution comparison with different values of lambda $(\lambda)$ 


\section{Conclusions and Future Directions}

Green supplier selection is a major milestone in transition towards the design and management of more environmentally sustainable supply chains. Most of modeling efforts for sustainable strategic supplier selection are based on the integration of fuzzy theory with conventional MCDM methods. In this paper, we developed a novel multi-objective programming model based on genetic algorithm to select sustainable strategic supplier under fuzzy environment. The model and algorithm are applied to a practical case in Pakistan. The experimental results and comparative sensitivity analysis illustrate the effectiveness of our proposed model. The suppliers play very important role in case of managing the quality, costs and services at desire level, which is affect the purchaser outcomes.

This research mainly investigated a multi-objectives expected value programming model with considering fuzzy coefficients for giving the solution of proposed problem. Genetic algorithm solution approach is proposed to get the optimal order allocation to suppliers for minimizing cost, maximizing quality and service levels. The main contributions of this paper are summarized below.

1. A general fuzzy multi-objective decision making (FMODM) model for sustainable strategic supplier selection based on genetic algorithm was presented. As mentioned, this model allowed for the incorporation of qualitative as well quantitative information expressed in linguistic and numeral terms considered as the aggregation of decision makers preferences.

2. An application example for (SSSS) problem at a Pakistani textile factory was given to verify the proposed approach. The study demonstrated the distinct characteristics of genetic algorithm. It was shown that the proposed algorithm could be used to obtain a better understanding of the complex solutions. The suggested technique is more efficient as compare to deterministic techniques for solving there all problem under uncertain environment. It can help the decision maker for ordering to different supplier for managing supply chain performance in efficient and effective manner.

3. This study provides a single platform for green supplier selection in a fuzzy environment and sets the stage for additional research in this important and growing knowledge area. The proposed model and solution approach is examined by a numerical example for checking the effectiveness, the results showed that it is effective and viable to solve the given numerical illustration. Because of conflicting nature of the multi-objectives and vagueness in the information related to the parameters of the decision variables, the deterministic techniques are not suitable to obtain an effective solution. 
Although the fuzzy expected value model with fuzzy coefficients constructed in present study should be helpful for solving real world problems, detailed analysis and further research is necessary to reveal more properties of a good method for solving other sector problems like agriculture, pharmaceutical, chemicals and services.

In the future, the researchers and practitioners can compare the results of this study with other fuzzy bi or tri level multi-objective techniques as well as multi-criteria tools such as fuzzy VIKOR, fuzzy ELECTRE, and fuzzy PROMETHEE may also be employed. Future researchers should pay more attention to the environmental objectives of supplier selection for different industries.

\section{Acknowledgements}

The authors would like to thank the Editor (Neslihan Demirel) and the anonymous referees for their very valuable and helpful suggestions for improving the quality of present research.

\section{References}

Aissaoui, N., Haouari, M., \& Hassini, E. (2007). Supplier selection and order lot sizing modeling: A review. Computers and Operations Research, 34(12), 3516-3540. https://doi.org/10.1016/j.cor.2006.01.016

Alinezad, A., Seif, A., \& Esfandiari, N. (2013). Supplier evaluation and selection with QFD and FAHP in a pharmaceutical company. International Journal of Advanced Manufacturing Technology, 68, 355-364. https://doi.org/10.1007/s00170-013-4733-3

Amid, A., Ghodsypour, H.S., \& Brien, O.C. (2006). Fuzzy multi objective linear model for supplier selection in a suppy chain. International journal of production economics, 104, 394-407. https://doi.org/10.1016/j.ijpe.2005.04.012

Amin, S.H., \& Zhang, G. (2012). An integrated model for closed-loop supply chain configuration and supplier selection: Multi-objective approach. Expert Systems with Applications, 39, 6782-6791. https://doi.org/10.1016/j.eswa.2011.12.056

Awasthi, A., Chauhan, S.S., \& Goyal, S.K. (2010). A fuzzy multi criteria approach for evaluating environmental performance of suppliers. International Journal of Production Economics, 126(2), 370-378. https://doi.org/10.1016/j.ijpe.2010.04.029 
Awasthi, A., Chauhan, S.S., \& Goyal, S.K. (2011). A multi-criteria decision making approach for location planning for urban distribution centers under uncertainty. Mathematical and Computer Modelling, 53(1), 98-109. https://doi.org/10.1016/j.mcm.2010.07.023

Banaeian, N., Mobli, H., Fahimnia, B., Nielsen, I.E., \& Omid, M. (2016). Green supplier selection using fuzzy group decision making methods: a case study from the agri-food industry. Computers \& Operations Research.https://doi.org/10.1016/j.cor.2016.02.015

Baskaran, V., Nachiappan, S., \& Rahman, S. (2012). Indian textile suppliers' sustainability evaluation using the grey approach. International Journal of Production Economics, 135, 647-658.

https://doi.org/10.1016/j.ijpe.2011.06.012

Buyukozkan, G., \& Cifci, G.(2011). A novel fuzzy multi-criteria decision framwork for sustainable supplier selection with incomplete information. Computers in Industry, 62(2), 164-174.

https://doi.org/10.1016/j.compind.2010.10.009

Chang, B., Chang, C.-W., \& Wu, C.-H. (2011). Fuzzy DEMATEL method for developing supplier selection criteria. Expert Systems with Applications: An International Journal, 38(3), 1850-1858. https://doi.org/10.1016/j.eswa.2010.07.114

Chen, C.T., Lin, C.T., \& Huang, S.F. (2006). A fuzzy approach for supplier evaluation and selection in supply chain management. International Journal of Production Economics, 102, 289-301. https://doi.org/10.1016/j.ijpe.2005.03.009

Chu, T.C., \& Varma, R. (2012). Evaluating suppliers via a multiple levels multiple criteria decision making method under fuzzy environment. Computers \& Industrial Engineering, 62, 653-660.

https://doi.org/10.1016/j.cie.2011.11.036

Degraeve, Z., \& Roodhooft, F. (2000). A mathematical programming approach for procurement using activity based costing. Journal of Business Finance and Accounting, 27(1-2), 69-98. https://doi.org/10.1111/14685957.00306

Dubois, D., \& Prade, H.(1994). Possibility theory: An approach to computerized processing of uncertainty). New York: Plenum press.

Dubois, D., \& Prade, H. (1997a). Fuzzy sets in approximate reasoning, Part 1: Inference with possibility distribution. Fuz:y Sets and Systems, 100, 73-132. https://doi.org/10.1016/S0165-0114(99)80008-6

Dubois, D., \& Prade, H. (1997b). The three semantics of fuzzy sets. Furzy Sets and Systems, 2(90), 141-150. https://doi.org/10.1016/S0165-0114(97)00080-8 
Fazlollahtabar, H., Mahdavi, I., Ashoori, M.T., Kaviani, S., \& Mahdavi-Amiri, N. (2011). A multi objective decision-making process of supplier selection and order allocation for multi-period scheduling in an electronic market. The International Journal of Advanced Manufacturing Technology, 52(9-12), 1039-1052. https://doi.org/10.1007/s00170-010-2800-6

Foerstl, K., Reuter, C., Hartmann, E., \& Blome, C. (2010). Managing supplier sustainability risks in a dynamically changing environment Sustainable supplier management in the chemical industry. Journal of Purchasing and Supply Management, 16(2), 118-130. https://doi.org/10.1016/j.pursup.2010.03.011

Gaballa, A.A. (1974). Minimum cost allocation of tenders. Operational Research Quarterly, 25(3), 389-398. https://doi.org/10.1057/jors.1974.73

Ghodsypour, S.H., \& O'Brien, C. (2001). The total cost of logistic in supplier selection, under conditions of multiple sourcing, multiple criteria and capacity constraint. International Journal of Production Economics, 73, 15-27. https://doi.org/10.1016/S0925-5273(01)00093-7

Govindan, K., Khodaverdi, R., \& Jafarian, A. (2013). A fuzzy multi-criteria approach for measuring sustainability performance of a supplier based on triple bottom line approach. Journal of Cleaner Production, 47, 345-354. https://doi.org/10.1016/j.jclepro.2012.04.014

Hashemian, S.M., Behzadian, M., Samizadeh, R., \& Ignatius, J. (2014). A fuzzy hybrid group decision support system approach for the supplier evaluation process. International Journal of Advanced Manufacturing Technology, 73(58), 1105-1117. https://doi.org/10.1007/s00170-014-5843-2

Hashim M., Yao, L., Nadeem, A.H., Nazim, M., \& Nazam, M. (2014). Multi-objective Optimization Model for Supplier Selection Problem in Fuzzy Environment. Proceedings of the Eighth International Conference on Management Science and Engineering Management. Advances in Intelligent Systems and Computing, 281, 1201-1213. Springer. https://doi.org/10.1007/978-3-642-55122-2_104

Iranmanesh, H., \& Thomson, V. (2008). Competitive advantage by adjusting design characteristics to satisfy cost targets. International Journal of Production Economics, 115, 64-71.

https://doi.org/10.1016/j.ijpe.2008.05.006

Jafar, R., Songhori, M., \& Mohammad, K. (2009). Fuzzy group decision making/fuzzy linear programming (FGDMLP) framework for supplier selection and order allocation. International Journal of Advance Manufacturing Technology, 43(5), 590-607.

Jauhar, S.K., Pant, M., \& Abraham, A. (2014). A novel approach for sustainable supplier selection using differential evolution: A case on pulp and paper industry. Intelligent data analysis and its applications, II, 105-117. Springer International Publishing. https://doi.org/10.1007/978-3-319-07773-4_11 
Kannan, D., Khodaverdi, R., Olfat, L., Jafarian, A., \& Diabat, A., (2013). Integrated fuzzy multi criteria decision making method and multi-objective programming approach for supplier selection and order allocation in a green supply chain. Journal of Cleaner Production, 47, 355-367.

https://doi.org/10.1016/j.jclepro.2013.02.010

Karpak, B., Kumcu, E., \& Kasuganti, R. (1999). An application of visual interactive goal programming: a case invendor selection decisions. Journal of Multi-Criteria Decision Analysis, 8, 93-105. https://doi.org/10.1002/(SICI)1099-1360(199903)8:2<93::AID-MCDA235>3.0.CO;2-\#

Kaslnqam, R., \& Glee, C.P. (2006). Selection of vendors-a mixed-integer programming approach. Computers and industrial engineering, 31(1), 347-350.

Katagiri, H., Sakawa, M., Kato, K., \& Nishizaki, I. (2008). Interactive multi objective fuzzy random linear programming: Maximization of possibility and probability. European journal of operational research, 188, 530-539. https://doi.org/10.1016/j.ejor.2007.02.050

Khatie, A.H., Bulgak, A., \& Segovia, J. (2010). Advanced decision support tool by integrating activity-based costing and management to systems dynamics. IEEE.

Kilic, S.H. (2013). An integrated approach for supplier selection in multi-item/multi-supplier environment. Applid mathematic and modelling, 37, 7752-7763. https://doi.org/10.1016/j.apm.2013.03.010

Kumar, M., Vrat, P., \& Shankar, R. (2006). A fuzzy programming approach for vener selection problem in a supply chain. International Journal of Production Economics, 101, 273-285.

https://doi.org/10.1016/j.ijpe.2005.01.005

Lee, A.H.I., Kang, H.-Y., Hsu, C.-F., \& Hung, H.-C. (2009). A green supplier selection model for hightech industry. Expert Systems with Applications, 36, 7917-7927. https://doi.org/10.1016/j.eswa.2008.11.052

Liao, Z., \& Rittscher, J. (2007). A multi-objective supplier selection model under stochastic demand condition. International Journal of Production Economics, 105, 150-159. https://doi.org/10.1016/j.ijpe.2006.03.001

Liou, H.J.J., Chuang, C.Y., \& Tzeng, H.G. (2013). A fuzzy integrad-based model for supplier evaluation and improvement. Information Sciences, 266, 199-217. https://doi.org/10.1016/j.ins.2013.09.025

Memon, M.S., Lee, Y.H., \& Mari, S.I. (2015). Group multi-criteria supplier selection using combined grey systems theory and uncertainty theory. Expert Systems with Applications, 42(21), 7951-7959. https://doi.org/10.1016/j.eswa.2015.06.018

Ordoobadi, S. (2009). Development of a supplier selection model using fuzzy logic. Supply Chain Management: An International Journal, 14(4), 314-327. https://doi.org/10.1108/13598540910970144 
Orji, I.M.J., \& Wei, S. (2014). A decision support tool for sustainable supplier selection in manufacturing firms. Journal of Industrial Engineering and Management, 7(5), 1293-1315. https://doi.org/10.3926/jiem.1203

Qiang, X., Hui, L., \& Xiao-Dong, Q. (2013). System dynamics simulation model for the electronic commerce credit risk mechanism research. International Journal of Computer Science Issues, 10(2).

Rezaei, J., \& Ortt, R. (2012). A multi-variable approach to supplier segmentation. International Journal of Production Research, 50(16), 4593-4611. https://doi.org/10.1080/00207543.2011.615352

Rodríguez, A., Ortega, F., \& Concepción, R. (2013). A method for the selection of customized equipment suppliers. Expert Systems with Applications, 40, 1170-1176. https://doi.org/10.1016/j.eswa.2012.08.021

Shidpour, H., Shahrokhi, M., \& Bernard, A. (2013). A multi-objective programming approach, integrated into the TOPSIS method, in order to optimize product design; in three-dimensional concurrent engineering. Computers \& Industrial Engineering, 64, 875-885. https://doi.org/10.1016/j.cie.2012.12.016

Singh, A. (2014). Supplier evaluation and demand allocation among suppliers in a supply chain. Journal of Purchasing \&Supply Management, 20, 167-176. https://doi.org/10.1016/j.pursup.2014.02.001

Songhori, M.J., Tavana, M., Azadeh, A., \& Khakbaz, M.H. (2011). A supplier selection and order allocation model with multiple transportation alternatives. The International Journal of Advanced Manufacturing Technology, 52(1-4), 365-376. https://doi.org/10.1007/s00170-010-2697-0

Soroor, J., Tarokh, M.J., Khoshalhan, F., \& Sajjadi, S. (2012). Intelligent evaluation of supplier bids using a hybrid technique in distributed supply chains. Journal of Manufacturing Systems, 31, 240-252. https://doi.org/10.1016/j.jmsy.2011.09.002

Su, R.H., Yang, D.Y., \& Pearn, W.L. (2011). Decision-making in a single-period inventory environment with fuzzy demand. Expert Systems with Applications, 38, 1909-1916. https://doi.org/10.1016/j.eswa.2010.07.123

Tako, A., \& Robinson, S. (2012). The application of discrete event simulation and system dynamics in the logistics and supply chain context. Decision Support Systems, 52, 802-815.

https://doi.org/10.1016/j.dss.2011.11.015

Wang-Chen, H.M., Chou, S.Y., Luu, Q.D., \& Yu, T.H.K. (2016). A Fuzzy MCDM Approach for Green supplier selection from the economic and environmental aspects. Mathematical Problems in Engineering, 2016. https://doi.org/10.1155/2016/8097386

Wang, D., \& Fang, S.C. (1997). A genetics-based approach or aggregate production planning in fuzzy environment. IEEE Transactions on Systems, Man, and Cybernetics, 27, 636-645. 
Weber, C.A., \& Currint, J.R. (2003). A multi-objective approach to vendor selection. European journal of operational research, 68(2), 173-184. https://doi.org/10.1016/0377-2217(93)90301-3

Wen, U.P., \& Chi, J.M. (2010). Developing green supplier selection procedure: ADEA approach. In Industrial Engineering and Engineering Management (IE\&EM), 2010 IEEE 17Th International Conference (70-74). IEEE. https://doi.org/10.1109/icieem.2010.5646615

Wu, D.(2008). Supply chain risk, simulation and vender selection. International Journal of Production Economics, 114, 646-655. https://doi.org/10.1016/j.ijpe.2008.02.013

Xu, J., \& Ding, C. (2011). A class of chance constrained multi objective linear programming with bi random coefficients and its application to vendors selection. International Journal of Production Economics, 131, 709-720. https://doi.org/10.1016/j.ijpe.2011.02.020

Xu, J., \& Yan, F. (2011). A multi-objective decesion making model for the vender selection problem in a bifuzzy environment. Expert systems with applications, 38, 9684-9695. https://doi.org/10.1016/j.eswa.2011.01.168

Xu, J., \& Zhou, X. (2011). Fuz:y-like multiple objective decision making (263). Berlin: Springer.

You, X.Y., You, J.X., Liu, H.C., \& Zhen, L. (2015). Group multi-criteria supplier selection using an extended VIKOR method with interval 2-tuple linguistic information. Expert Systems with Applications, 42(4), 1906-1916. https://doi.org/10.1016/j.eswa.2014.10.004

Zadeh, L. (1965). Fuzzy sets. Information and Control, 8, 338-353. https://doi.org/10.1016/S0019-9958(65)90241$\mathrm{X}$

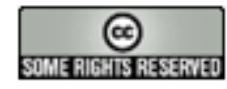

Article's contents are provided on an Attribution-Non Commercial 3.0 Creative commons license. Readers are allowed to copy, distribute and communicate article's contents, provided the author's and Journal of Industrial Engineering and Management's names are included. It must not be used for commercial purposes. To see the complete license contents, please visit http://creativecommons.org/licenses/by-nc/3.0/. 